\title{
O enredo da diversificação produtiva no rural de Arroio do Tigre/RS 1
}

Resumo: Este trabalho trata de analisar a diversificação produtiva no município de Arroio do Tigre/RS. Faz-se apontamentos sobre a diversificação agrícola com as suas limitações internas e externas, a caracterização das propriedades, as estratégias de reprodução e as expectativas de intervenção estatal pelos agricultores familiares. As famílias, grosso modo, não se dedicam exclusivamente à cultura do tabaco, tendo, em sua propriedade, um leque de produtos de autoconsumo e algumas culturas voltadas ao mercado como estratégia de apoio à reprodução dos agricultores familiares no espaço rural.

\section{The plot of diversification of production in rural Arroio do Tigre/RS}

Abstract: This work deals with analyzing the diversification of production in the municipality of Arroio do Tigre/ RS. It will be notes on agricultural diversification with its internal and external constraints, characterization of the properties, reproductive strategies and expectations of state intervention by family farmers. Families, roughly, not exclusively engaged in tobacco cultivation, taking his property a range of products consumption and some cultures as a market-oriented strategy to support the reproduction of family farmers in rural areas.
Tecnólogo em Agropecuária: Sistemas de Produção (UERGS) Administração(ULBRA); Especialista em Gestão Pública Municipal (UFSM); Mestre e Doutorando em Extensão Rural (UFSM).

Palavras-chave:
Diversificação Produtiva;
Tabaco; Estratégias de
Reprodução; Arroio do Tigre.
Key-words: Productive
Diversification; $\quad$ Tobacco;
Reproductive $\quad$ Strategies;
Arroio do Tigre.

1 Este trabalho integra a dissertação de mestrado do autor desenvolvida no Programa de Pós-Graduação em Extensão Rural (PPGExR) da Universidade Federal de Santa Maria (UFSM) no período 20092011. Uma versão preliminar do artigo foi apresentada no $5^{\circ}$ Encontro da Rede de Estudos Rurais, em Junho de 2012, na cidade de Belém, Pará. 
${ }^{2}$ A região denominada Território Centro Serra engloba os seguintes municípios: Arroio do Tigre, Cerro Branco, Estrela Velha, Ibarama, Jacuizinho, Lagoa Bonita do Sul, Lagoão, Passa Sete, Salto do Jacuí, Segredo, Sobradinho e Tunas. Nesse trabalho, optou-se pela composição de municípios que envolvem o Território Centro Serra, segundo definição estabelecida, atualmente, pelo Ministério do Desenvolvimento Agrário (MDA). Outras configurações espaciais são realizadas, mas, para efeitos dessa análise, opta-se pela classificação contemporânea do governo federal.

${ }^{3} 0$ módulo rural do município é 20 hectares.

Geografia Ensino \& Pesquisa, v. 16, n.3 p. $37-48$, set./dez.. 2012

O enredo da diversificação produtiva no rural de

Arroio do Tigre/RS

\section{Introdução}

Este artigo objetiva iniciar uma reflexão sobre a diversificação produtiva, bem como analisar a diversidade agrícola no meio rural, usando como perspectiva empírica o município de Arroio do Tigre/RS. Nesse sentido, busca-se compreender a temática sobre a perspectiva dos agentes, destacando o viés discursivo das famílias agriculturas e traçando uma relação com as estratégias de reprodução de ciclo curto (anuais). Para compreender os elementos que estão presentes na racionalidade dos agricultores, o estudo pautou-se por uma breve revisão simultânea sobre a temática intercalando com incursões entre as famílias rurais em questão.

O município de Arroio do Tigre, localizado no Território Centro Serra² do Rio Grande do Sul (Fig.01), possui aproximadamente 12.648 habitantes, segundo dados da Fundação de Economia e Estatística (FEE DADOS, 2010), sendo que destes, 5.962 (47,14\%) encontram-se na área urbana e os demais 6.686 (52,86\%), em áreas rurais. Em 2009, o PIB per capita do local é de $\mathrm{R} \$ 15.776,00$.

Figura 1 - Mapa de localização do território Centro Serra - Rio Grande do Sul

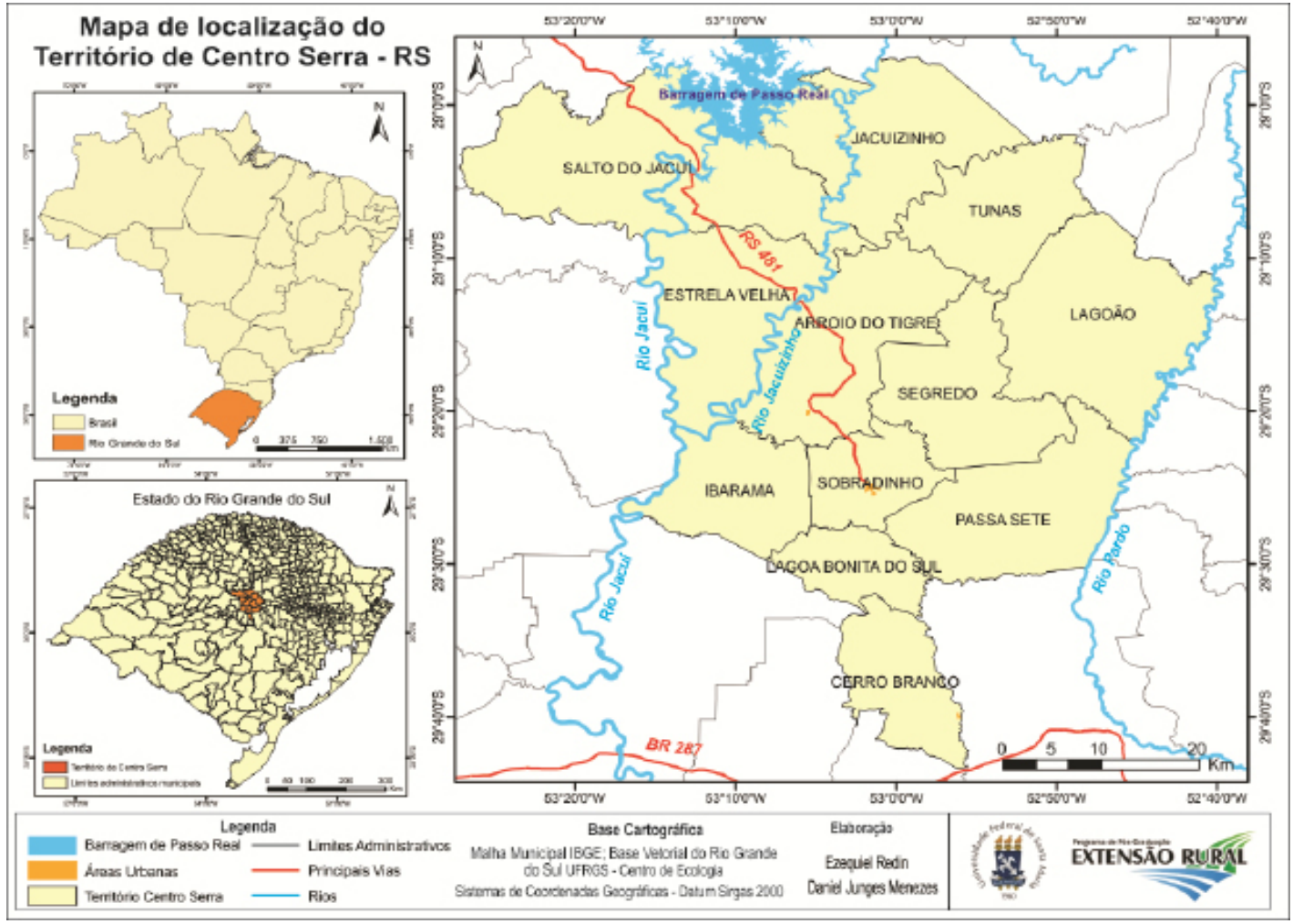

Município potencialmente agrícola, destaca-se pela produção de fumo, milho, trigo, feijão, soja, pecuária de corte e leite e produtos voltados para o autoconsumo. Com característica diversificada, o tabaco torna-se o principal ingresso de renda, pois envolve uma produção altamente especializada com um valor final superior a culturas voltadas a larga escala. Em 2010, Arroio do Tigre liderou a produção de fumo em folha no Centro Serra com 12.687 toneladas. No mesmo ano, produziu 15.180 toneladas de soja, 23.400 toneladas de milho, 1.661 toneladas de feijão e 1.008 toneladas de trigo, conforme a FEE Dados.

Arroio do Tigre é um município assinalado, principalmente, pelo que representa no âmbito de produção agrícola. Assim como nos demais municípios da região, há predominância de pequenas e médias propriedades, com uma produção agropecuária bastante intensiva e diversificada ${ }^{3}$. É um dos municípios-referência quando 0 assunto envolve as peculiaridades, as dificuldades, os incentivos, as ações e as intervenções na agricultura. Com uma base, essencialmente, voltada para a pequena escala, no entanto, a produção total fornece destaque ao município, em âmbito de região (diversidade de culturas agrícolas), Estado (principalmente o feijão) e país (no caso do fumo). A configuração espacial 
do território evidencia características particulares, que apontam para locais com maior possibilidade de expansão das atividades agrícolas, envolvendo produção de maior escala, especialmente, nos lugares abrangidos pelas áreas planas. Outra conformação apresentada diz respeito à maior declivosidade, marcando uma área agricultável que evoca para um maior trabalho braçal, produzindo em menor expressão. Em ambos, o cultivo do fumo é destaque, no entanto, no segundo, apresenta maior ênfase, maior qualidade e grau mais acentuado de especialização.

Tratar sobre diversificação é complicado. Sem dúvida, um tema deveras amplo e, ademais, complexo. 0 dicionário conceitua como: "tornar diferente, fazer variar" (LUFT, 2000). Verificando que o termo diversificação é complexo, nesse trabalho, optou-se por compreender a diversificação como aquela atividade agrícola que envolve o exercício de mais de dois produtos na propriedade rural no mesmo período agrícola e não necessariamente voltada para a comercialização; e que complemente as necessidades básicas da família agricultora, sendo que, na existência de excedentes, possa gerar renda para a manutenção financeira da unidade produtiva. Em relação à especialização da produção, Schneider (1994, p. 6) afirma que é "o cultivo intensivo de monoculturas fortemente integradas aos mercados".

Para essa discussão, usou-se a técnica de entrevistas abertas com finalidade exploratória sobre o enredo da diversificação. Ao total, foram realizadas vinte e uma entrevistas sendo quatorze agricultores (dois por distrito do município). Além disso, compuseram a amostra mais dois técnicos da Emater, dois profissionais ligados à Secretaria do Meio Ambiente e Agropecuária, um presidente da cooperativa e um da Secretaria da Agricultura, sendo que, nesses últimos, buscaram-se informações gerais do local para identificar as familias agricultoras a serem pesquisadas. Ainda integrou a investigação um técnico ligado à iniciativa privada, o qual pertence a uma empresa fumageira.

A partir disso, recortaram-se algumas declarações das famílias agricultoras, agentes de desenvolvimento e técnicos da iniciativa privada, contrastando com experiências a campo, visitas, diálogos e entrevistas com diversos atores rurais (principalmente, agricultores de tabaco) ${ }^{4}$, caracterizando uma pesquisa de fonte primária. Com isso, foi possível sistematizar e discutir as dificuldades e os impasses estabelecidos no rural local, o discurso da diversificação em áreas de tabaco e as concepções em torno do desenvolvimento, principalmente, econômico. Desse modo, as informações discutidas, através do método qualitativo, referem-se às entrevistas realizadas em 2010 com agricultores que representam, grosso modo, uma generalização do local estudado.

\section{Diversificação agrícola - reflexões a partir da agricultura familiar fumageira}

Na agricultura familiar, o grau de diversificação, talvez, está diretamente vinculado a mão de obra apta na propriedade agrícola. A qualidade da mão de obra é preponderante quando envolve 0 conhecimento das técnicas aplicadas no plantio, na colheita e na cura, no caso do tabaco. Por outro lado, as atividades mais "braçais" podem ser realizadas sem nenhuma dificuldade, portanto, a qualificação da mão de obra somente é exigida na impossibilidade das pessoas da família, que detêm o saber-fazer, não estarem presente no momento. Ao contrário, a repetição das atividades por algumas semanas coloca 0 indivíduo nas mesmas condições para efetuar o trabalho, muitas vezes árduo, da lavoura. Godelier (1971, p. 38) complementa: "a produtividade do trabalho não se mede apenas em termos técnicos e não depende apenas de condições técnicas, depende também das condições sociais".

Nesse sentido, Redin (2011a) alerta para a eminência de conflitos na gestão do trabalho familiar no rural. Uma empresa, por exemplo, tem seus funcionários sob a jurisdição da Constituição das Leis do Trabalho (CLT), mas, em casos de extrema desobediência ou insatisfação do empresário com o colaborador, simplesmente, ele pode ter a opção encerrar o seu contrato individual do trabalho, assim demitindo-o, com suas respectivas penalidades financeiras. Portanto, o trabalhador do setor empresarial pode ser considerado um fator de produção descartável, pois é passível de substituição por outro que tenha, ao menos, condições mínimas de qualificação, ou ainda esse outro pode
${ }^{4}$ Por questão de ética e sigilo, os depoentes foram identificados por nomes fictícios não remetendo a imagem do agricultor.

Geografia Ensino \& Pesquisa, v. 16, n.3 p. 37-48, set./dez. 2012

Redin, E.

ISSN 2236-4994 
passar por um processo de treinamento. O caso, porém, torna-se diferente quando o indivíduo de conflito no trabalho é uma pessoa da família (mulher, filho ou parente próximo), que o agricultor não pode ou, teoricamente fica mais difícil desconsiderar um membro do grupo, primeiro, porque é um integrante da família - a princípio um sucessor da terra (caso for filho (a)) -, e segundo, por ser um elemento que pode agregar na produtividade do trabalho. Portanto, a priori, o integrante da família no meio rural não é um fator de produção descartável, sendo que é desejável a sua manutenção e o seu auxílio nas atividades agrícolas, posto que, em caso contrário, pode acontecer uma possível migração deste para a busca de um espaço no meio urbano, através de várias formas, seja pela procura de qualificação profissional (educação) ou por uma atividade urbana (REDIN, 2011a).

A produção agrícola de Arroio do Tigre é bastante distinta, congregando propriedades bem diversificadas. $O$ discurso da "diversificação" paira na concepção de que os agricultores cultivam apenas a monocultora do tabaco, sendo, por isso, especializados. Na verdade, a especialização é uma das atividades do sistema de produção, entretanto, a tese sobre a monocultura não corrobora com o local de estudo, como já destacou, em certa medida, também Paulilo (1990, p. 168), “(...) pois o fumo é compatível com qualquer tamanho de propriedade, exigindo apenas 2 ha de terra (...)". De tal modo que a diversificação compete além da exigência de área agricultável disponível (caso for uma atividade agrícola), em mais mão de obra, investimentos, conhecimento das técnicas das atividades, assistência técnica, logística e comercialização, além de mercado disponível, isto é, toda uma estrutura de apoio desde a produção até a venda.

Em curto e médio prazo, haverá um aumento no consumo do tabaco, sendo que a redução deve acontecer no longo prazo. Destarte, no médio prazo, a diminuição da produção de fumo poderia estar coligada na disseminação de alternativas produtivas que combinassem rentabilidades equivalentes àquela proporcionada pela fumicultura com sistemas de integração que propiciassem aos produtores facilidade de acesso ao crédito, garantia de preço e comercialização, assistência técnica, enfim, características que estão presentes no sistema de integração do fumo e que são incentivos para a manutenção dos produtores na atividade (SOUZA, 2009).

A preocupação dos agricultores em encontrar a melhor forma de reprodução social constitui em adaptar as estratégias, conforme a sua realidade diante de suas limitações e possibilidades palpáveis. É uma forma de resposta diante da necessidade de manutenção da família no meio rural, usando estratégias de diversificação, de incrementação e de consolidação, diante do cenário a que estão expostos. A diversificação para 0 autoconsumo fortalece 0 atendimento das necessidades familiares, contribuindo para que o excedente possa ser redistribuído nas relações pessoais como produtos de troca ou de venda. As estratégias de incrementação na atividade escolhida perfazem o uso de técnica diferenciada ou alternativa, proporcionando, às vezes, um produto final de melhor qualidade. As estratégias de consolidação equivalem a um conjunto de ações de fortalecimento da unidade de produção e da família que se reproduz nela. Não se chegou a abordar com mais ênfase as estratégias pluriativas e as rendas não agrícolas, pois não é o propósito deste estudo, mas se deve reconhecer que são essenciais para o fortalecimento da agricultura familiar.

Agricultores que possuem maior apropriação do saber, processo conjugado entre o conhecimento externo adquirido através de técnicos e o saber empírico calcado em experiência positiva ou negativa na atividade, são circunstanciais para a continuidade de uma estratégia de reprodução que, anteriormente, não estava fornecendo resultados favoráveis. Agricultores com maior acesso à assistência técnica (não derivada das agroindústrias fumageiras) têm maior confiança em investir em estratégias com maior grau de risco. A assistência técnica subjetivamente aumenta o nível de segurança do agricultor na atividade pela sua fidúcia no conhecimento externo dos agentes de extensão rural. No entanto, a desconfiança também pode prevalecer. Percebeu-se, no local empírico, que agricultores menos integrados à atividade fumageira, portanto, com alto grau de diversificação, sobressaem-se aos agricultores menos diversificados, em relação à dependência de renda de uma única atividade, no entanto, o fator trabalho e o custo da contratação de mão de obra são muito elevados. Agricultores mais especializados e com boa qualidade no produto final, a curto prazo, estão mais capitalizados. 


\section{Além da diversificação produtiva - limitantes e dificuldades}

Devido à grande diversidade de produtos agrícolas na propriedade, a falta de mão de obra é evidente. Nas palavras do agricultor: "...a questão da diversificação nossa, isso nos complica a vida. É muito complicado, vou ter que desistir do feijão ou mecanizar toda a área, ou seja, plantar somente onde a área é mecanizável". Essa afirmação corrobora com as escritas de Garcia Filho (1999, p. 24): "Se o fator mais limitante da produção for a mão-de-obra disponível, os produtores provavelmente optarão por sistemas mais extensivos, que utilizam equipamentos e máquinas que reduzem o trabalho por unidade de área".

$\mathrm{O}$ ato de diversificar pode tanto consolidar a propriedade como determinar altos prejuízos no momento da colheita pela competição do trabalho por outras atividades. A inexistência de mão de obra, mesmo contratada, é um fator limitante para a tomada de decisão do agricultor. Em uma propriedade, encontrou-se a produção de soja, milho, feijão, trigo, fumo, uva, pêssego, morango, repolho, avicultura, produção de mel, produção de suínos como as atividades mais prevalecentes, além das estratégias de reprodução básicas e complementares ${ }^{5}$. Questionou-se o Sr. Cléber sobre qual seria a sua principal atividade atualmente. Ele pensou e disse: "Eu, na verdade, não tenho uma atividade principal. As mais importantes são o feijão, soja, milho, trigo. Tá, mas tem caminhão que também me rende". A dificuldade de estabelecer uma atividade principal na unidade de produção é característica de sua alta diversificação. Esse agricultor é um dos poucos que usa a feira livre municipal para comercializar os seus produtos diretamente ao consumidor. Existe uma particularidade muito grande nesse caso.

Assim sendo, havia a intenção de compreender porque o agricultor ainda produzia fumo, em virtude dessa diversidade de produção, além de uma agroindústria de cárneos, nem citada até o momento por ele. A produção do fumo, em nossa percepção, é movida muito mais por uma causa do que por uma identidade produtiva. Nas suas palavras, a produção seria uma forma de demonstrar aos outros agricultores que não era necessário quase revolvimento do solo, como é prática de muitos na região. Para o agricultor, quanto menor for o revolvimento, a tendência é ter um produto final com mais qualidade, menor degradação do solo e menor esforço. Seu depoimento acrescenta: "Essas carreiras de fumo que eu e a gurizada plantamos, só para mostrar que dá para produzir fumo sem trabalhar muito. Eu sou inimigo de trabalhar muito, mas eu trabalho muito e muito". Observa-se, desse modo, a tentativa de buscar estratégias que diminuem a labuta na atividade fumicultora, comportamento, um tanto, condicionado pelas outras diversas atividades que mantém, que, igualmente, demandam muita mão de obra.

Questionou-se, além disso, sobre a sua agroindústria familiar, uma das poucas legalizadas pelo CISPOA, em Arroio do Tigre/RS. Acreditava-se que esse empreendimento era uma forma de agregação de valor e o maior responsável pelo ingresso de renda na propriedade. Quando se mencionou, a frustração foi aparente, pelos problemas enfrentados com a legalização do empreendimento. A agroindústria foi construída com uma verba a fundo perdido da prefeitura municipal e integrou mais dois sócios (vizinhos). No depoimento do agricultor: "na época ganhamos $\mathrm{R} \$ 56.000,00$ a fundo perdido da prefeitura que conseguiu uma verba especial. Aí o que aconteceu? Nós achávamos que, com $\mathrm{R} \$ 70.000,00$, nós faríamos! E quando fomos fazer e tudo instalado, adivinha quanto isso custou para nós? Custou $\mathrm{R} \$ 400.000,00$. Foi muito dinheiro".

0 alto custo mensal da legalização (aproximadamente $R \$ 3.000,00$ ), a má gestão administrativa (deixado a cargo de um filho dos sócios) e a necessidade de escala de produção são fatores que apresentaram dificuldades iniciais. Segundo o agricultor, os primeiros meses tiveram um resultado negativo de aproximadamente $\mathrm{R} \$ 64.000,00$. Para cobrir essas despesas foi necessário comercializar toda a sua produção de milho, além do montante investido pelos outros sócios. A inflexibilidade da legislação sanitária que não diferencia grandes empreendimentos de agroindústrias familiares rurais é um dos motivos pelos quais muitos agricultores, que trabalham com baixa escala de produção, não conseguem reproduzir. A agonia está presente no depoimento do Senhor Cléber ao falar sobre 0 assunto:

\footnotetext{
${ }^{5}$ Nesse sentido, Redin (2011b, p. 241-242) identifica três tipos de estratégias para 0 município de Arroio do Tigre/RS, assim sendo: a) estratégia de reprodução principal: designa a cultura do fumo como a base estrutural das unidades de produção, servindo como principal orientação financeira e determinando a alocação dos fatores de produção e a presença (em maior ou menor grau) de outros sistemas de produção; b) estratégia de reprodução complementar: envolvem os produtos agrícolas voltados para a comercialização do excedente como o milho, trigo, feijão e soja (voltado somente para venda) e atividade de pecuária de corte e leite, em alguns casos. A principal função é servir como complementação de renda, consolidando e fornecendo segurança em eventuais dificuldades ou frustrações de safra da atividade principal; c) estratégia de reprodução básica: tem característica voltada, principalmente, para o autoconsumo da família sendo em raros casos comercializados. Em determinadas propriedades, dependendo da contingência, pode existir uma transição entre a estratégia de reprodução básica e a complementar.
}

Geografia Ensino \& Pesquisa, v. 16, n.3 p. 37-48, set./dez. 2012

Redin, E.

ISSN 2236-4994 41 
A legislação nessas alturas complica nossa vida. Um dia desses, chega o fiscal e viu que nossas portas eram tudo de ferro, disse que nós teríamos 30 dias para trocar todas as portas de inox. E aí? São quase $\mathrm{R} \$ 8.000,00$. Hoje, a agroindústria está legalizada, as vendas estão boas, mas essas são as vendas que têm que ser em grande quantidade. Tempo atrás, a gente produzia e chegava no final do mês e não custava $R \$ 1,00$ e agora? Nada contra os informais, eu compro cinco porcos aí e carneio; ganho meus $R \$ 1.000$ ou $R \$ 1.500,00$ e não custa nada. $A$ legislação dessa agroindústria de linguiça aí, ela tem a mesma coisa que você que mata cinco mil porcos por dia. É a mesma. Ela não diferencia de uma de grande porte. Rapaz, se eu fosse depender da agroindústria eu estava frito sem banha. Queimadinho! Devendo para Deus e todo mundo.

Os produtos derivados das pequenas agroindústrias familiares concorrem diretamente em custos, escala de produção e preço final com as grandes indústrias do mesmo setor. As agroindústrias familiares rurais visualizadas como alternativas aos agricultores familiares pela sua capacidade de agregar valor e ingresso de renda na propriedade emperram sua viabilidade perante o processo de indiferenciação e a concorrência de seus produtos com aquelas de maior porte. Nesse caso, fica evidente que a agroindústria familiar legalizada, por enquanto, não é uma estratégia de reprodução viável à agricultura familiar, principalmente, àqueles pouco capitalizados. A composição das estratégias de reprodução no âmbito da produção agrícola é viável e compensadora, enquanto não existir uma oferta demasiada dos produtos no mercado. Portanto, as estratégias de diversificação idênticas para toda uma região não mostram resultados significativos, quando se planeja reduzir expressivamente as lavouras de tabaco, como afirma o agricultor: "Mas não temos condições de absorver todos os agricultores de fumo para essas atividades. Não existe, não tem saída dessa forma. Se todos vão começar a produzir leite. Não adianta!".

\section{Caracterização das propriedades, estratégias de reprodução e expectativas de intervenção estatal}

A adoção de uma estratégia de reprodução em massa não terá resultados positivos na possível substituição do fumo, pelo contrário, acarretará em novo problema que passa pela lei da oferta e da demanda local, principalmente. Se uma das estratégias básicas (autoconsumo) transpassarem para atividade principal, a sua abrangência territorial limitada provocará um excesso de oferta, causando consequências negativas que podem afetar a reprodução social das famílias agricultoras. Por outro lado, o tabaco tem demanda em nível mundial e o maior foco de produção é - Sul do Brasil, grosso modo, por tais motivos que a atividade abarca tantas famílias agricultoras, sem que uma maior oferta local traga sérias complicações. De modo análogo a experiência, mesmo não sendo uma análise generalizável (o caso do agricultor), que também produz fumo, mostra a diversidade de situações com que eles deparam-se no rural. Na tabela 01, apresentam-se as características gerais presentes nas propriedades do município. 
Tabela 01- Características das propriedades rurais em Arroio do Tigre/RS

\begin{tabular}{|c|c|c|c|}
\hline \multirow{2}{*}{ Características } & \multicolumn{3}{|c|}{ Influência dos elementos na gestão da propriedade } \\
\cline { 2 - 4 } & $\begin{array}{c}\text { Agricultores c/ maior área } \\
\text { cultivada de fumo }\end{array}$ & $\begin{array}{c}\text { Agricultores c/ área } \\
\text { média cultivada de } \\
\text { fumo }\end{array}$ & $\begin{array}{c}\text { Agricultores com área } \\
\text { pequena } \\
\text { Cultivada }\end{array}$ \\
\hline Mão de Obra & Alta & Alta & Alta \\
\hline Penosidade do trabalho & Alta & Alta & Alta \\
\hline Restrição ambiental & Alta & Média & Baixa \\
\hline Emprego de Tecnologia & Alta & Alta & Alta \\
\hline Escala de produção & Alta & Média & Baixa \\
\hline Diversificação & Baixa & Média & Alta \\
\hline Especialização no fumo & Alta & Média & Baixa \\
\hline Relação com a indústria & Relativamente dependente & Menos dependente & Pouco dependente \\
\hline Fidelidade com indústria & Alta & Média & Alta \\
\hline
\end{tabular}

Fonte: Pesquisa de campo, 2010

Org.: Ezequiel Redin.

Os agricultores de Arroio do Tigre possuem outras estratégias concomitantes a atividade do fumo, no entanto, o grau de diversificação voltado para o mercado nas unidades agrícolas dependerá da quantidade de tabaco plantado e da área disponível. Caso a área for pequena, a diversificação limita-se a produtos estritamente para o autoconsumo da família, tendo uma alta especialização no fumo; e, diante da maior disponibilidade do fator terra, a tendência é que se aumente 0 grau de diversificação até certo ponto. Áreas muito grandes, geralmente, tendem a especializarem-se no cultivo da soja ou milho, esse último como subproduto da atividade leiteira e comercialização. A relação e a fidelidade com a indústria são um processo altamente inconstante e permeado por cooperações e conflitos, sendo muito variável, dependendo do caso.

Nessa perspectiva, os atores rurais entendem que dada a necessidade da redução do consumo do tabaco e o incentivo à diversificação nas propriedades, os agricultores encarregam o Estado a trabalhar no sentido de promover mecanismos parecidos ou idênticos ao sistema de integração do tabaco. Observou-se, ao cogitar sobre os projetos de diversificação do governo federal, que os produtores não repudiam a ideia, ao contrário, apóiam-na, mas salientam que é inviável uma unidade de produção basear-se unicamente pelas atividades propostas até então, caso uma possivel substituição do tabaco, pela inexistência de uma estrutura de apoio, sendo assim, aparato muito distante do sistema do tabaco em que se encontram atualmente. Portanto, na ausência do Estado, o sistema de integração do fumo tem suprido as necessidades dos agricultores protegerem-se ou minimizarem os riscos, garantindo a compra e certo preço mínimo.

Na opinião dos agricultores, os programas e as políticas para a produção de alimentos não são suficientes para garantir que a pequena propriedade consiga reproduzir a família, convergindo para um retorno gradual ao esforço abdicado nas atividades. Quando não é o alto custo de produção, é o preço baixo de comercialização e a falta de um preço mínimo que, ao menos, cubra os custos na atividade. Quando indicam usar outra tática que não envolva as normais estratégias de reprodução complementares são afetados pelas altas taxas de legalização e impostos, como salienta o chefe de família, Senhor Cleber: "Nós temos umas parreiras. Para legalizar a produção de vinho você tem que estar dentro dos padrões (...). Para vender um litro de vinho, vai pagar $40 \%$ de ICM. Se vender um litro de vinho por $R \$ 10,00$, ninguém vai querer comprar. Desses, tenho que dar $R \$ 4,00$ para 0 governo. Não tem como suportar isso. Então, a cada R $\$ 100,00$ eu pago $R \$ 40,00 "$.

Os agricultores familiares, segundo Prieb (2005), anseiam pelo aumento de renda familiar e procuram estratégias para a sua reprodução. No entanto, a sua manutenção depende do

Geografia Ensino \& Pesquisa, v. 16, n.3 p. 37-48, set./dez. 2012

Redin, E.

ISSN 2236-4994 
aproveitamento das possibilidades do mercado e de sua rápida orientação para as atividades maiores geradoras de renda. Entretanto, isso pode ser uma relevante carência no rural, pois os incentivos estatais para o desenvolvimento de atividades no meio rural, além de escassos, apenas privilegiam atividades agrícolas que sempre se esforçou para desenvolver a produção e a produtividade, deixando de lado as novas oportunidades de rendas criadas, oriundas do próprio estágio de desenvolvimento capitalista, alcançado também nas zonas rurais, que poderiam assegurar novas perspectivas no meio rural. As determinantes econômicas mais gerais podem incidir positivamente (períodos de grande demanda por fumo) e negativamente (queda da demanda) sobre a agricultura familiar. A permanência de produtores familiares depende do alcance de políticas públicas, sendo que essas não estão sujeitas à boa vontade dos governantes, mas ao poder de barganha que reflete essencialmente a capacidade organizativa das famílias de interlocução junto ao poder público.

Existe 0 desejo de cessar com a produção de fumo, no entanto, a racionalidade econômica prevalece no sentido de reproduzir-se no curto prazo. A motivação em sustentar-se economicamente de outra atividade menos danosa à saúde fica dependente da impossibilidade que 0 atrelamento ao mercado sugere ao agricultor. Nessa concepção, existe uma dependência da cultura do fumo pela alta rentabilidade e, em menor expressão, pela conduta das agroindústrias. Talvez, o grau de dependência ao tabaco possa reduzir substancialmente quando existirem alternativas viáveis e em curto prazo que, ao menos, garantam uma rentabilidade similar ao tabaco. Parece evidente que 0 fator mais relevante para a mudança de estratégia de reprodução principal é a renda bruta que a cultura/atividade proporciona à unidade de produção. $O$ depoimento do agricultor Walter mostra repulsa a outras atividades, evidenciando uma possível decisão limitada: "Mas vai fazer o quê? Vai produzir porco a preço de custo, não sobra nada. Se você produzir um porco de seis meses vai te sobrar $\mathrm{R} \$ 10,00$ ou $\mathrm{R} \$ 20,00$. Ou você cria muito porco ou não cria. Não adianta! Com quatro hectares de milho, não sobra nada. Em comparação ao fumo, não tem nem como comparar".

A atividade familiar é gerida pela produção agrícola voltada para o mercado, mas os alimentos para 0 autoconsumo são produzidos em grande parte das propriedades. A diferença básica que abrange a chamada diversificação da atividade na propriedade envolve dois tipos: a) diversificação para o autoconsumo; b) diversificação para a comercialização. A primeira aparece em unidades agrícolas com áreas menores, inclinadas e com significativas restrições, necessitando uma produção mais intensiva, portanto, sustentando as estratégias de reprodução básicas. A segunda envolve propriedades com maior área, possivelmente, com acesso à mecanização. Desse modo, quando se trata de diversificação é necessário analisar por qual viés ela está sendo abordada.

Nessa pesquisa, procurou-se desvendar a opinião dos agricultores sobre a especialização na atividade fumageira, pelo pressuposto de ser uma atividade estritamente comercial que ocupa, em grande parte, a mão de obra familiar, deixando, possivelmente, evidências sobre uma menor diversificação de produtos alimentícios. Tal hipótese é descartada por Etges (1991) que afirma não existir monocultura do fumo, mas que há pequenas explorações produtoras e, ao mesmo tempo, existem outras unidades onde o fumo não é cultivado. Conforme Paulilo (1990), a introdução da fumicultura numa propriedade não significa uma mudança de ramo, mas uma atividade a mais.

Geralmente, entre os produtores de fumo tipo Virgínia são estabelecidos comparações sobre a sua especialização, traduzindo ideias de que não produzem alimentos para o consumo. Realizouse esse questionamento ao Senhor Harley e obteve-se a seguinte explanação:

Geografia Ensino \& Pesquisa, v. 16, n. 3 p. $37-48$, set./dez.. 2012

O enredo da diversificação produtiva no rural de

Arroio do Tigre/RS
Plantá, a maioria planta. Alguns não plantam, mas não é tanto como aqueles que produzem Burley. Mas eles plantam milho. Quem tem mais terra, planta até soja. Plantam milho até para vender. Depende da propriedade e da quantidade de terra. Nós que temos uma área pequena, nós não podemos fazer isso aí, mas, no caso do meu irmão, ele tem uma propriedade grande (tipo uns 30 hectares), então eles plantam para vender de tudo. Eles plantam três tipos de fumo: Comum, Burley e Virgínia. Plantam milho, feijão e soja, mandioca, batatinha. Uma lavoura assim de tudo. E ainda não contrata ninguém, só eles. É que eles têm quatro 
pessoas na família. E eles trabalham em conjunto, onde os vizinhos um ajuda o outro. Mas, às vezes, não dá certo esse negócio de um ajudar o outro porque dá a safra na mesma semana.

O cultivo do Burley, por demandar menor mão de obra na colheita, pode facilitar a produção de alimentos para o mercado como o feijão, por exemplo. Parece que o determinante não é a mão de obra quando se tratam das culturas comerciais como a soja, o trigo e o milho, mas a quantidade de terra e 0 acesso à mecanização. A produção para 0 autoconsumo da família parece estar presente nas atividades dos agricultores. O Secretário da Agricultura de Arroio do Tigre proferiu a situação da seguinte forma: "Quem somente planta fumo e nenhum produto para comer está passando por uma situação delicada porque precisa comprar tudo, mas aqui são poucos que fazem isso". Procedeu-se à mesma interrogação ao orientador técnico para a sua avaliação (Quem planta fumo tipo Virginia não planta alimentos?), sem cerimônia, ele respondeu rapidamente:

\begin{abstract}
A maioria planta, mas sempre tem aquele que não planta, mas é minoria. 0 que 0 pessoal está deixando de lado é o feijão, por causa do preço e compete a colheita dele com a do fumo no Natal e Ano Novo, geralmente. Nesse momento é o pico de colheita de estufa, de Burley, é tudo nessa época. Então, nessa época, está complicado. E outra, por causa da mão de obra, estão parando. Você vai pagar 350 a 400 reais para arrancar um saco de feijão plantado. Daí, não precisa explicar mais nada porque não se planta. Muitos não produzem produtos para vender, mas para o consumo próprio se produz tipo a galinha, o porco, mandioca, batata, batatinha. Essas coisas todo mundo produz. Para notar isso é só acompanhar nós para ver se você não consegue batata, mandioca, melancia. Qualquer casa que você pedir tem isso! Os agricultores até te fornecem de graça, porque eles têm de sobra.
\end{abstract}

A coerência no discurso dos analistas, dos técnicos e dos próprios agricultores demonstra que existe produção para o autoconsumo (estratégia de reprodução básica), talvez, dependendo das restrições, não atingindo o mercado. Se for levada em consideração que a diversificação está atrelada às várias atividades dentro da propriedade, pode-se afirmar que os agricultores do município não são especializados, mesmo tendo como orientação o cultivo do tabaco. Por outro lado, se o ponto de análise é o ingresso de renda na propriedade, grosso modo, o fumo torna-se a atividade preponderante, sendo responsável pelo maior percentual do capital. As estratégias complementares fortalecem a estratégia principal, mas nem, de perto, chegam a substituí-la. No depoimento antagônico do Senhor Robinson, agricultor, nota-se uma expressiva tentativa de se definir:

Sei lá, acho que somos mais especializados no fumo, mas, do milho, a gente precisa na propriedade, sem milho não dá, porque o nosso milho, a maioria, é plantado na terra de fumo. Plantam toda a terra de fumo com milho, temos que aproveitar o adubo. Nós plantamos para comer além do feijão, mandioca, batata, amendoim, batatinha. Essas coisas de horta, nós plantamos tudo, tomate, cebola, alface, repolho, e assim vai. A carne e a banha, o cara faz. Eu acho que Arroio do Tigre é o que mais produz de tudo.

Verifica-se que acreditam ser especializados no tabaco por conhecer as técnicas e fortalecer-se financeiramente desta atividade. No entanto, apresentam produtos característicos de uma agricultura de autoconsumo com a presença de produção oriunda para o consumo interno. Nesse sentido, é possível interpretar que, talvez, o fumo possa ser uma estratégia fundamental estando atrelada à consolidação de outras estratégias para permanecer no rural. Continuando a conversa, identificou-se que a família tem rendas não-agrícolas, quando o chefe da família, em períodos de baixo pico de mão de obra na propriedade, trabalha como assistente de pedreiro em obras no município e a esposa, às vezes, trabalha em uma empresa fumageira durante o período

Geografia Ensino \& Pesquisa, v. 16, n. 3 p. 37-48, set./dez. 2012

Redin, E.

ISSN 2236-4994 
de comercialização. Não obstante, as estratégias de reprodução não estão vinculadas somente à questão produtiva, o que alerta para uma necessidade de buscar meios para incrementar a renda na unidade de produção. $O$ depoimento do Senhor Edson sobre as suas atividades adverte:

Sou um produtor de tudo, planto feijão, milho, soja, gado, porco, mas a principal renda seria o fumo. As outras atividades é um quebra-galho. Se o fumo dá uma zebra como ano passado, entra a soja, entra o gado para tapar os custos. Mas o negócio é o clima, esse ano, o fumo está bom, só se dá um contratempo para não poder colher, mas se tu ver, eu não colhi nem $30 \%$ e já terminei 350 varas, se eu tivesse varas, daria mais de 2.000 varas só para desbaixerar. Então, não tem como dar errado, só uma tempestade mesmo para dar prejuízo esse ano.

A quantidade de terra disponível na propriedade proporciona que a diversificação para 0 mercado seja em maior ou menor grau. A concepção do agricultor mostra que a estratégia de reprodução principal é o tabaco, usando a expressão "quebra-galho" para evidenciar as atividades de reprodução complementares que fornecem segurança na iminência de uma safra frustrada. 0 fator segurança aparece novamente na produção do tabaco, emergindo risco na atividade, apenas se o clima tiver um desvio de comportamento normal. O discurso do Senhor Willian, agricultor em Linha Taquaral, região onde o fumo Virginia prevalece é muito similar: "Nós plantamos coisa de comer como a batatinha, feijão, batata, mandioca, milho. Mas a atividade de renda é o fumo". 0 plantio "pro gasto" sustenta a unidade de produção, não necessitando adquiri-lo fora da propriedade. Esses produtos, geralmente, não são valorizados pelos agricultores por não significarem ingressos financeiros à propriedade, mas eles sabem a respeito da sua importância na composição alimentar da família. Completando a argumentação, Senhor Willian apresenta a sua realidade:

Tenho nove hectares, onde planto quatro hectares de fumo. E planto uns cantos, onde tenho 0 feijão, a mandioca e outros só para o consumo da família. Além do fumo, eu vendo o milho, esse eu planto na resteva do fumo. 0 milho é colhido tudo a mão, nossas lavouras não dá para colocar máquina. Ano passado colhemos 300 sacos de milho.

O fator mão de obra condiciona, além da quantidade e da diversidade de produtos, a escolha sobre qual tipo de fumo que a família irá cultivar. A escolha do fumo tipo Virgínia, além de necessitar um investimento superior em ativo imobilizado, necessita maior demanda de mão de obra, como salienta Senhor Walter:

Precisa mais mão de obra, precisa quatro pessoas, assim, com duas, você faz a lavoura, e o fumo de estufa precisa ter quatro pessoas para encher um forno e daí não é fácil e depois cuidar o forno a noite toda, colocando lenha. Então, é muito prejudicial a saúde. O Burley você colhe uma carroçada e coloca no galpão e vai dormir e o forno [de estufa] tem que cuidar a noite toda para fazer artigo [qualidade]. Ele é mais rentável, mas aí já tem que ter pessoal.

O depoimento do agricultor apresenta as desvantagens de ingressar na produção de Virgínia

Geografia Ensino \& Pesquisa, v. 16, n.3 p. 37-48, set./dez.. 2012

O enredo da diversificação produtiva no rural de

Arroio do Tigre/RS outro quadrante, o cultivo desse tabaco proporciona, às vezes, um retorno financeiro mais significativo. A transição de várias famílias para o fumo tipo Virgínia no município não levou em consideração tais fatores, mas os rumores de que o fumo tipo Burley seria restringido pela tentativa de coibir os aromatizantes e os açucares do cigarro. As estratégias de adaptação, nessa realidade, orientam-se por uma lógica que indica uma estratégia de reprodução restrita, pela alternância de tipo de tabaco, continuando na atividade. A resistência nesse sistema de produção, sem dúvida, é pela sua alta 
renda bruta por hectare. A preservação de uma atividade desse gênero evoca uma simplificação e um descrédito das alternativas para diminuir a dependência da renda do fumo. Arguido sobre os programas de diversificação geridos pelo governo federal, o Senhor Harley, responde de forma frustrada:

\begin{abstract}
Não dá certo. Tu não tem rentabilidade. Por exemplo, hoje, eu vou plantar repolho. Vou plantar 30 mil pés de repolho. Tá, vou vender a um real o pé, vai dar 30 mil reais. Ah, então deu dinheiro! Ano que vem, o meu vizinho vai plantar mais 30 mil pés de repolho. Daí, outro ano, mais um vizinho. $E$ assim dois, três vizinhos já vão plantar. Por fim, ninguém vai mais querer repolho. Você não consegue vender. Daí, só vai valer 0,20 ou 0,30 centavos. Que lucro tu vai ter?
\end{abstract}

As estratégias que envolvem a produção de alimentos parecem, rapidamente, saturar o mercado, implicando diretamente no preço pago pelo produto. 0 exemplo do repolho é um caso típico e volátil, parecido com o cultivo do feijão em que, em alguns anos, agricultores recebem $\mathrm{R} \$$ 150,00 a saca de $60 \mathrm{~kg}$ e, em anos posteriores, com um custo de produção mais elevado, o produto não atinge acima do patamar de $\mathrm{R} \$ 70,00$. Talvez, a consideração do Senhor Cléber aproxime-se ao depoimento anterior: "Você vai fazer assim também, outro vai fazer igual e daí todo mundo quebra (...) mas não temos condições de absorver todos os agricultores de fumo para essas atividades. Não existe, não tem saída dessa forma. Se todos vão começar a produzir leite. Não adianta".

A necessidade de garantia de preço fica evidente em quase todas as respostas que encaminham uma possível solução de renda na área agrícola, como sustenta Senhor Clementino: "O dia que alguém vier e falar para os produtores assim: vocês podem plantar tal coisa que nós vamos comprar tudo a tal preço, daí todo mundo vai plantar. Agora, o dia que isso vai acontecer, eu quero ver". Com ar de frustração em relação à produção de alimentos no mercado, os agricultores sustentam uma insatisfação por ter apenas o fumo como única atividade que ainda podem conseguir resultados expressivos, necessitando de muito trabalho e atenção, como salienta Senhor Willian: "Agora, se você plantar o fumo, colher e abandonar as terras. Daí o ano que vem você, somente, vai querer plantar de novo, pode parar que dá prejuízo. Então é uma cultura que tem que caprichar e ter dedicação".

O desânimo, nas expressões dos agricultores, fica evidente quando comentam sobre as variações e as instabilidades do mercado agrícola ou as leis restritivas ou punitivas na agricultura. 0 caso emergente da possível restrição do fumo tipo Burley, em um município com maior produção do gênero, implica em agricultores mais jovens, atitude de indignação e frustração com as atividades agrícolas que não remuneram de acordo com o teor do seu trabalho.

\title{
Considerações finas
}

A investigação possibilitou identificar que o município, diante da orientação para a cultura do tabaco, apresenta um leque interessante de produtos agrícolas voltados para o mercado, bem como para o consumo da família e da propriedade (REDIN, 2011c). Ultrapassando a questão meramente produtiva, destaca-se, ainda, um fenômeno que se observou nos contatos com as famílias entrevistadas, o que se denominou necessidade de reconhecimento e a esperança de que a agricultura poderá ainda Ihes proporcionar um desenvolvimento equiparável a outras formas de renda, trazendo-Ihes a oportunidade de adquirir bens e serviços que possam facilitar o seu trabalho e propiciarem condições de desenvolvimento e reprodução social.

As familias almejam ter condições de preparar os filhos para a sucessão, inclusive, possibilitando-lhes educação e um ensino superior para estarem aptos a, talvez, tornarem as propriedades mais lucrativas. Como todos, inclusive a sociedade urbana, os agricultores possuem ambições e necessidades em curto prazo, portanto, clamam por soluções rápidas e emergentes.

Geografia Ensino \& Pesquisa, v. 16, n.3 p. 37-48, set./dez. 2012

Redin, E.

ISSN 2236-4994 
Não estão aptos e pacientes a esperar um chamado desenvolvimento rural em longo prazo que, talvez, poderá não ser útil para a sua ambição, nessa jornada, em que, como agricultor, necessita previamente reproduzir-se em uma sociedade que é mediada pelas relações do capital. Assim sendo, a racionalidade do agricultor, talvez, seja a mesma de qualquer indivíduo que labuta por dias melhores.

\section{Referências Bibliográficas}

ETGES, V. E. Sujeição e resistência: os camponeses gaúchos e a indústria do fumo. Santa Cruz do Sul: FISC, 1991.

GARCIAFILHO, D. P. Guia metodológico de diagnóstico de sistemas agrários. Brasília, FAO/ INCRA, 1999.

GODELIER, M. Antropologia Econômica. In: COPANS, J. et al. Antropologia, ciência das sociedades "primitivas"? Lisboa, Edições 70, 1971. (Org.) Godelier: antropologia. [tradução de Evaldo Sintoni et al]. São Paulo: Ática, 1981.

LUFT, C. P. Dicionário. Português, São Paulo: Ática, 2000.

PAULILO, M. I. S. Produtor e agroindústria: consensos e dissensos. O caso de Santa Catarina. Florianópolis: Editora da UFSC, 1990.

PRIEB, R. I. P. Pluriatividade na produção familiar fumageira. Santa Cruz do Sul: Edunisc, 2005.

REDIN, E. Dentro e fora da porteira - os elementos condicionantes na estratégia de reprodução dos agricultores familiares fumageiros. Extensão Rural. Santa Maria: DEAER/PPGExR - CCR - UFSM, Ano XVIII, nº 22, p. 67-102, Jul - Dez de 2011a.

REDIN, E. Entre o produzir e o reproduzir na agricultura familiar fumageira de Arroio do Tigre/ RS. 2011b. 262p. Dissertação (Mestrado em Extensão Rural) PPGExR/UFSM, Santa Maria, 2011.

REDIN, E. Potencialidades agrícolas: Arroio do Tigre em cena. Geografia. Ensino \& Pesquisa (UFSM). Santa Maria, v. 15, p. 227-24, 2011c.

SCHNEIDER, S. O Desenvolvimento Agrícola e as Transformações da Estrutura Agrária nos Países Desenvolvidos: a pluriatividade. Revista Reforma Agrária, ABRA, Campinas, v. 24, n. 03, p.106-132, 1994.

SOUZA, R. P. Convenção-Quadro para Controle do Tabaco: reflexões sobre o futuro da fumicultura brasileira. In: CONGRESSO DA SOCIEDADE BRASILEIRA DE ECONOMIA, ADMINISTRAÇÃO E SOCIOLOGIA RURAL, 47., 2009, Porto Alegre. Anais... Porto Alegre: UFRGS, 2009. 19p.

\section{Correspondência:}

Ezequiel Redin - Av. Roraima - MEPG/CEU III Apt. n 5221- Bairro Camobi. CEP: 97.105-340 - Santa Maria - RS

Geografia Ensino \& Pesquisa, v. 16, n. 3 p. $37-48$, set./dez.. 2012

O enredo da diversificação produtiva no rural de

Arroio do Tigre/RS
E-mail: ezequielredin@gmail.com

Recebido em 18 de abril de 2012.

Revisado pelo autor em 15 de agosto de 2012.

Aceito para publicação em 25 de agosto de 2012. 